\title{
Assessing Antibiotic Stewardship Program (ASP) Implementation: Psychometric Properties of Survey measures based on the Consolidated Framework for Implementation Research (CFIR)
}

Jorie Michaela Butler ( $\square$ jorie.butler@hsc.utah.edu )

University of Utah https://orcid.org/0000-0003-4519-7997

Ellen Childs

Boston University

Tamar F. Barlam

Boston University

Mari-Lynn Drainoni

Boston University

\section{Caitlin Reardon}

Ann Arbor VA Medical Center: VA Ann Arbor Healthcare System

\section{Yue Zhang}

University of Utah Division of Epidemiology Biostatistics: The University of Utah Division of Epidemiology

\section{Laura Damschroder}

Ann Arbor VA Medical Center: VA Ann Arbor Healthcare System

\section{Peter Taber}

University of Utah

Karl Madaras-Kelly

Idaho State University

Matthew Bidwell Goetz

UCLA: University of California Los Angeles

\section{Eddie Stenehjem}

Intermountain Healthcare

Jincheng Shen

University of Utah Division of Epidemiology Biostatistics: The University of Utah Division of Epidemiology

\section{Matthew Samore}

University of Utah Division of Epidemiology Biostatistics: The University of Utah Division of Epidemiology

\section{Research}

Keywords: Implementation, Consolidated Framework for Implementation Research (CFIR), Survey, antibiotic stewardship programs, Confirmatory Factor Analysis (CFA), measurement instrument, validity

Posted Date: June 1st, 2021

DOI: https://doi.org/10.21203/rs.3.rs-553383/v1

License: (c) (i) This work is licensed under a Creative Commons Attribution 4.0 International License. Read Full License 


\section{Abstract}

Background: Antibiotic stewardship programs (ASPs) are crucial to prevent the emergence of antibiotic resistance and to improve outcomes for patients. Few measurement instruments examine ASP implementation. A validated instrument rooted in implementation science theory will increase our understanding of ASP implementation and enable comparisons across studies.

Methods: We used the Consolidated Framework for Implementation Research (CFIR) to guide development of ASP implementation measures. Survey questions were developed by infectious disease and survey design experts to assess 22 potential determinants of implementation across five domains of the CFIR. Survey items were reviewed by CFIR experts for face and content validity. Antibiotic stewards (infectious disease pharmacists and physicians) were recruited from 154 Veterans Affairs (VA) hospital and Intermountain Healthcare $(\mathrm{IH})$ sites to complete the survey. Survey responses were aggregated by site, and results were determined at the site level. We conducted confirmatory factor analyses (CFA) to assess structural validity of measures and evaluated inter-item consistency.

Results: A total of 182 stewards completed the survey (155 VA and $27 \mathrm{IH}$ responses). At least one response was obtained from 126 hospitals (81.8\%). CFAs for most CFIR constructs exhibited good fit (CFI > .90; TLI > .90; RMSEA $<.05$, SRMR < .08). Scale reliabilities ranged from .54-.96 indicating low to strong inter-item consistency. Determinants that were rated highly present at the sites (across site means ${ }^{3} 4.0$ or above) included Self-Efficacy, Engaging, Evidence Strength and Quality and Relative Advantage, indicating stewards found ASP evidence compelling and felt their personal involvement was effective in engendering positive results for the ASP.

Conclusions: Psychometric properties measured via CFA indicate validity of our CFIR-based measure of determinants for ASP implementation outcomes. This is the first validated set of measures based on the CFIR for ASP implementation and the first to include measures for 4 out of five CFIR domains. These validated measures will help to provide much needed understanding of barriers and facilitators of ASP implementation. Research and quality improvement teams can use these measures to identify contextual determinants of ASP implementation and use this information to guide selection of strategies and compare results across multiple studies.

\section{Contributions To The Literature}

- We used the Consolidated Framework for Implementation Research (CFIR) to develop a survey for antibiotic stewards to assess implementation at their hospitals.

- We validated the survey using psychometric methods.

- These validated measures will help to provide understanding of barriers and facilitiators of Antibiotic stewardship program implementation.

\section{Background}

The rise of antibiotic resistant infections constitutes a public health emergency, to which response is crucial (1-4). Antibiotic stewardship programs (ASPs) have been found to be successful in reducing inappropriate prescribing, improving patient outcomes, and curbing antibiotic resistance $(5,6)$. ASP implementation is required for hospitals by the Centers for Medicare and Medicaid Services (CMS) (7-10). ASP implementation may include a wide range of activities, such as patient-level interventions, prospective audit and feedback, de-escalation, clinician education, and tracking antibiotic use patterns $(11,12)$. ASPs also monitor patterns of antibiotic resistance in their healthcare system and report key information to hospital leadership and government agencies (13). ASP's constitute extremely complex interventions with multiple layers including activities to support both patient health, population health, and that may operate on competing time frames and require changing physician behavior. Implementation of ASPs across diverse hospital settings, provides crucial opportunities to compare experiences and identify determinants of successful ASP implementation.

Page 2/21 
Despite widespread recognition of the importance of ASPs, few accepted measures exist to assess their implementation based on direct feedback from antibiotic stewards. Existing surveys for stewards have not been relevant for ASP implementation. For example, one survey assesses stewards' perceptions of legal issues in stewardship consultation $(14,15)$, while a second focuses on their perceptions of an ASP intervention in their hospital (16). Other ASP-related surveys have elicited information from providers, for example surveying knowledge among recent medical school graduates (17), assessing nurse or pharmacist support for stewardship activities (18), and examining intentions to participate in stewardship activities (e.g., pharmacist intention to fill a "wait and see" prescription) (19) (20). Whereas some ASP surveys have addressed specific implementation activities, none have used a design grounded in implementation science theory to identify facets of ASP implementation that may differentiate between more and less successful programs. To address the lack of validated research tools that assess determinants of successful ASP implementation, we developed a survey for stewards using the Consolidated Framework for Implementation Research (CFIR).

Implementation is a complex endeavor characterized by social and contextual facets. The CFIR is rooted in knowledge from many disciplines, including organizational change and psychology. It provides a conceptual foundation for studying implementation by defining a "menu" of constructs potentially associated with implementation effectiveness. As a result, it provides a systematic, comprehensive, and tailorable approach to uncovering drivers of variability in implementation outcomes. The CFIR consists of five broad domains: 1. Characteristics of the Intervention, 2. Outer Setting, 3. Inner Setting, 4. Characteristics of Individuals, and 5. Process. Domains are comprised of constructs that describe more specific influences within the domain; the CFIR contains a total of 39 constructs distributed among the five domains $(21,22)$. The CFIR has been used to assess implementation of many types of innovations across diverse settings, from trauma and informed care(23) to sustaining surgical safety checklists $(24,25)$. However, some constructs have not been quantitatively measured, limiting the opportunity for construct measure validation. Our objective was to develop measures of determinants across the CFIR's five domains and assess psychometric validity of those measures in the context of ASP implementation. This validation will permit future work examining implementation of stewardship across facilities using our survey measures.

\section{Methods}

\section{Study Settings and Approach}

The current analysis is one component of a large mixed-methods study of antibiotic stewardship at 20 Intermountain Healthcare $(\mathrm{IH})$ hospitals in the Western United States and 134 Veterans Health Administration (VHA) hospitals across the country. Barlam et al. conducted qualitative interviews with stewards from a subset of those hospitals to examine the perspectives on stewardship at their sites(26). Our study examines the psychometric properties of the survey that informed those interviews, evaluating evidence of face validity (agreement that a survey measures what it purports to measure). We evaluated construct validity of the survey using confirmatory factor analysis (CFA). We assessed discriminant validity of the factors and internal consistency of the variables of each model. In addition, we reviewed site-level survey responses for CFIR determinants (barriers and facilitators).

\section{Survey Development}

In 2017 the study team developed initial survey items via team consensus. Members of the study team who are antibiotic stewardship experts (MS, TB, MG, KMK, ES)) and implementation science, survey methodology, or CFIR experts (CR, LD, MD, EC, JB) used the online CFIR technical assistance website (27) to develop survey items. These experts iteratively shared questions which were then discussed by the entire study team at length. Once a preliminary version of the survey was created, study team CFIR experts (Reardon, Damschroder) reviewed and edited the survey to ensure items represented the intended CFIR domains and constructs. The survey was then modified and piloted with antibiotic stewards. Final revisions incorporated suggestions from all levels of review and piloting.

\section{Final Survey Characteristics}


The final survey comprised 72 items representing all five CFIR domains and 22 CFIR constructs within the context of antibiotic stewardship implementation. The 22 specific constructs were selected because of their relevance to ASP implementation.

The number of measurement items per domain ranged from 2 (Outer Setting) to 21 (Inner Setting). Survey respondents rated items on a Likert scale from 1 to 5 , where 1 represented "strongly disagree" and 5 represented "strongly agree", with an additional "don't know" option. See Table 1, column 1 for CFIR domains and column 2 for CFIR constructs measured in this survey along with all survey items in column 3. (INSERT Table 1) 
CFIR Domains, Constructs, and Survey Items

\begin{tabular}{|c|c|c|c|c|}
\hline CFIR Domain & CFIR Construct & Survey Item & $\begin{array}{l}\text { Variable } \\
\text { Label }\end{array}$ & CFA Models \\
\hline \multirow{5}{*}{$\begin{array}{l}\text { Intervention } \\
\text { Characteristics }\end{array}$} & \multirow{2}{*}{$\begin{array}{l}\text { Evidence Strength } \\
\text { and Quality }\end{array}$} & \multirow{2}{*}{$\begin{array}{l}\text { Academic literature confirms that } \\
\text { ASPs are an effective way to improve } \\
\text { antibiotic prescribing. }\end{array}$} & \multirow[t]{2}{*}{ EV1 } & MODEL 1 \\
\hline & & & & $\begin{array}{l}\text { Evidence Strength \& } \\
\text { Quality/Relative } \\
\text { Advantage (4 items) }\end{array}$ \\
\hline & & $\begin{array}{l}\text { Clinical experience confirms that ASPs } \\
\text { are an effective way to improve } \\
\text { antibiotic prescribing. }\end{array}$ & EV2 & \\
\hline & Relative Advantage & ASPs add value to our organization. & EV3 & \\
\hline & & $\begin{array}{l}\text { ASPs appear to have more } \\
\text { advantages than disadvantages for } \\
\text { our patients. }\end{array}$ & EV4 & \\
\hline \multirow[t]{2}{*}{ Outer Setting } & Peer Pressure & $\begin{array}{l}\text { Knowing that other peer hospitals } \\
\text { were instituting an ASP was a factor in } \\
\text { deciding to implement one here. }\end{array}$ & PPX & $\begin{array}{l}\text { NOT MODELED } \\
\text { (insufficient item number } \\
\mathrm{n}=2 \text { ) }\end{array}$ \\
\hline & Cosmopolitanism & $\begin{array}{l}\text { Talking to other organizations with } \\
\text { ASPs helped us develop our ASP. }\end{array}$ & $\mathrm{CX}$ & \\
\hline \multirow[t]{11}{*}{ Inner Setting } & \multirow{2}{*}{$\begin{array}{l}\text { Networks and } \\
\text { Communication }\end{array}$} & \multirow{2}{*}{$\begin{array}{l}\text { In this hospital, clinical staff's } \\
\text { opinions are solicited regarding } \\
\text { decisions about patient care. }\end{array}$} & \multirow[t]{2}{*}{ NC1 } & \\
\hline & & & & $\begin{array}{l}\text { Networks and } \\
\text { Communication/Relative } \\
\text { Priority (3 items) }\end{array}$ \\
\hline & & $\begin{array}{l}\text { Communication within the hospital is } \\
\text { effective. }\end{array}$ & NC2 & \\
\hline & $\begin{array}{l}\text { Implementation } \\
\text { Climate: Relative } \\
\text { Priority }\end{array}$ & $\begin{array}{l}\text { Hospital leadership sets a high priority } \\
\text { on the success of the ASP. }\end{array}$ & NC3 & \\
\hline & \multirow[t]{4}{*}{ Culture } & \multirow{2}{*}{$\begin{array}{l}\text { Staff at the hospital have a sense of } \\
\text { personal responsibility for improving } \\
\text { patient care and outcomes. }\end{array}$} & \multirow[t]{2}{*}{$\mathrm{C} 1$} & MODEL 3 \\
\hline & & & & Culture (3 items) \\
\hline & & $\begin{array}{l}\text { Staff at the hospital cooperate to } \\
\text { maintain and improve effectiveness of } \\
\text { patient care. }\end{array}$ & $\mathrm{C} 2$ & \\
\hline & & $\begin{array}{l}\text { Staff at the hospital are receptive to } \\
\text { change in clinical processes. }\end{array}$ & $\mathrm{C} 3$ & \\
\hline & $\begin{array}{l}\text { Implementation } \\
\text { Climate: }\end{array}$ & $\begin{array}{l}\text { Clinicians at my facility view ASPs as } \\
\text { one of the more important }\end{array}$ & $\mathrm{IC} 1$ & MODEL 4 \\
\hline & Compatibility & & & $\begin{array}{l}\text { Compatibility/Learning } \\
\text { Climate/Implementation } \\
\text { Climate (4 items) }\end{array}$ \\
\hline & $\begin{array}{l}\text { Implementation } \\
\text { Climate: } \\
\text { Compatibility }\end{array}$ & $\begin{array}{l}\text { The ASP has been easily integrated } \\
\text { into the Electronic Health Record } \\
\text { (EHR) system. }\end{array}$ & IC2 & \\
\hline
\end{tabular}

*Constructs included in combined models are indicated by model number and number of total items displayed in column 4.

** Variable labels (e.g., EV1) match Fig. 1 indicating for which variable loading is reported. number. 


\begin{tabular}{|c|c|c|c|c|}
\hline \multirow[t]{4}{*}{ CFIR Domain } & CFIR Construct & Survey Item & $\begin{array}{l}\text { Variable } \\
\text { Label }\end{array}$ & CFA Models \\
\hline & $\begin{array}{l}\text { Implementation } \\
\text { Climate: Learning } \\
\text { Climate }\end{array}$ & $\begin{array}{l}\text { In this hospital, clinical staff's } \\
\text { opinions are solicited regarding } \\
\text { innovative, new programs. }\end{array}$ & IC3 & \\
\hline & & $\begin{array}{l}\text { Clinical innovation and creativity to } \\
\text { improve patient care are rewarded in } \\
\text { my hospital. }\end{array}$ & IC4 & \\
\hline & $\begin{array}{l}\text { Readiness for } \\
\text { Implementation: } \\
\text { Leadership } \\
\text { Engagement }\end{array}$ & $\begin{array}{l}\text { Hospital leadership was involved in } \\
\text { the initial development of the ASP. }\end{array}$ & LEX & $\begin{array}{l}\text { NOT MODELED } \\
\text { (insufficient item number } \\
\mathrm{n}=2 \text {; if tested in } \\
\text { combination with other } \\
\text { readiness variables did not } \\
\text { meet fit indices thresholds. }\end{array}$ \\
\hline & & $\begin{array}{l}\text { Hospital leadership provided adequate } \\
\text { resources to establish the ASP. }\end{array}$ & LEX & \\
\hline & $\begin{array}{l}\text { Readiness for } \\
\text { Implementation: } \\
\text { Leadership } \\
\text { Engagement }\end{array}$ & $\begin{array}{l}\text { Our hospital primarily started the ASP } \\
\text { because it was mandated. }\end{array}$ & LE1 & $\begin{array}{l}\text { MODEL } 5 \\
\text { Leadership Engagement (6 } \\
\text { items) }\end{array}$ \\
\hline & & $\begin{array}{l}\text { There was an internal push from } \\
\text { hospital leadership to establish an } \\
\text { ASP. }\end{array}$ & LE2 & \\
\hline & & $\begin{array}{l}\text { There was an ASP-champion on the } \\
\text { clinical staff who actively promoted } \\
\text { the implementation of the ASP. }\end{array}$ & LE3 & \\
\hline & & $\begin{array}{l}\text { Clinical leadership has endorsed the } \\
\text { project in visible ways. }\end{array}$ & LE4 & \\
\hline & & $\begin{array}{l}\text { Clinical leadership gives the antibiotic } \\
\text { steward the authority to enforce the } \\
\text { ASP policies. }\end{array}$ & LE5 & \\
\hline & & $\begin{array}{l}\text { The Antibiotic steward(s) has } \\
\text { protected time to implement the ASP. }\end{array}$ & LE6 & \\
\hline & $\begin{array}{l}\text { Readiness for } \\
\text { Implementation: } \\
\text { Access to } \\
\text { Knowledge and } \\
\text { Information }\end{array}$ & $\begin{array}{l}\text { The EHR provides helpful reports } \\
\text { about antibiotic use within the } \\
\text { hospital. }\end{array}$ & AK1 & $\begin{array}{l}\text { MODEL } 6 \\
\text { Access to Knowledge and } \\
\text { Information ( } 3 \text { items) }\end{array}$ \\
\hline & & $\begin{array}{l}\text { Clinicians and hospital staff have } \\
\text { received enough education and } \\
\text { training on the ASP. }\end{array}$ & AK2 & \\
\hline & & $\begin{array}{l}\text { The ASP is integrated into new } \\
\text { provider training. }\end{array}$ & AK3 & \\
\hline $\begin{array}{l}\text { Characteristics } \\
\text { of Individuals }\end{array}$ & $\begin{array}{l}\text { Knowledge and } \\
\text { Beliefs about the } \\
\text { Intervention }\end{array}$ & The staff was receptive to the ASP. & KB1 & $\begin{array}{l}\text { MODEL } 7 \\
\text { Knowledge and Beliefs } \\
\text { about the Intervention (9 } \\
\text { items) }\end{array}$ \\
\hline
\end{tabular}

*Constructs included in combined models are indicated by model number and number of total items displayed in column 4.

** Variable labels (e.g., EV1) match Fig. 1 indicating for which variable loading is reported. number. 


\begin{tabular}{|c|c|c|c|c|}
\hline CFIR Domain & CFIR Construct & Survey Item & $\begin{array}{l}\text { Variable } \\
\text { Label }\end{array}$ & CFA Models \\
\hline & & $\begin{array}{l}\text { Nursing and other support staff } \\
\text { understand the importance of the ASP } \\
\text { policies. }\end{array}$ & KB2 & \\
\hline & & $\begin{array}{l}\text { ASP policies put a heavy burden on } \\
\text { the nursing staff. }\end{array}$ & KB3 & \\
\hline & & $\begin{array}{l}\text { Clinical Pharmacists who provide } \\
\text { patient care on the inpatient wards } \\
\text { understand the importance of the ASP } \\
\text { policies. }\end{array}$ & KB4 & \\
\hline & & $\begin{array}{l}\text { ASP policies put a heavy burden on } \\
\text { Clinical Pharmacists who provide } \\
\text { patient care on inpatient wards. }\end{array}$ & KB5 & \\
\hline & & $\begin{array}{l}\text { Clinicians do not like the ASP because } \\
\text { they feel it limits their ability to treat } \\
\text { patients the way they think is best. }\end{array}$ & KB6 & \\
\hline & & $\begin{array}{l}\text { Clinicians think the ASP delays } \\
\text { antibiotic therapy too much. }\end{array}$ & KB7 & \\
\hline & & $\begin{array}{l}\text { Clinicians think the ASP restricts too } \\
\text { many antibiotics. }\end{array}$ & KB8 & \\
\hline & & $\begin{array}{l}\text { The ASP involves too many steps for } \\
\text { clinicians to adhere to in prescribing } \\
\text { antibiotics. }\end{array}$ & KB9 & \\
\hline & & $\begin{array}{l}\text { It is important to me that my hospital } \\
\text { does not have substantially higher } \\
\text { antibiotic use than other hospitals. }\end{array}$ & KB10 & \\
\hline & Self-efficacy & $\begin{array}{l}\text { I have a lot of authority in the } \\
\text { antibiotic decisions made in my } \\
\text { facility. }\end{array}$ & SE1 & MODEL 8 \\
\hline & & & & Self-efficacy (9 items) \\
\hline & & $\begin{array}{l}\text { I provide options to clinicians in } \\
\text { antibiotic decisions in my facility. }\end{array}$ & SE2 & \\
\hline & & $\begin{array}{l}\text { I accept responsibility for the } \\
\text { outcomes of this program. }\end{array}$ & SE3 & \\
\hline & & $\begin{array}{l}\text { I feel like I can effect change in my } \\
\text { setting. }\end{array}$ & SE4 & \\
\hline & & $\begin{array}{l}\text { I feel like I have the skills to function } \\
\text { effectively in my role. }\end{array}$ & SE5 & \\
\hline
\end{tabular}

*Constructs included in combined models are indicated by model number and number of total items displayed in column 4.

** Variable labels (e.g., EV1) match Fig. 1 indicating for which variable loading is reported. number. 


\begin{tabular}{|c|c|c|c|c|}
\hline \multirow[t]{5}{*}{ CFIR Domain } & \multirow[t]{4}{*}{ CFIR Construct } & Survey Item & $\begin{array}{l}\text { Variable } \\
\text { Label }\end{array}$ & CFA Models \\
\hline & & $\begin{array}{l}\text { I am able to carry out the mission of } \\
\text { the ASP in my hospital. }\end{array}$ & SE6 & \\
\hline & & $\begin{array}{l}\text { I am empowered to continue to } \\
\text { improve the ASP. }\end{array}$ & SE7 & \\
\hline & & $\begin{array}{l}\text { I am invested in the success of the } \\
\text { ASP. }\end{array}$ & SE8 & \\
\hline & $\begin{array}{l}\text { Individual } \\
\text { Identification with } \\
\text { Organization }\end{array}$ & $\begin{array}{l}\text { It is important to me that my hospital } \\
\text { does not have substantially higher } \\
\text { antibiotic use compared to other } \\
\text { hospitals. }\end{array}$ & IIX & $\begin{array}{l}\text { NOT MODELED } \\
\text { (Insufficient item number } \\
n=1)\end{array}$ \\
\hline \multirow[t]{14}{*}{ Process } & \multirow[t]{6}{*}{ Planning/Executing } & $\begin{array}{l}\text { When the ASP was initially developed, } \\
\text { roles and responsibilities were clearly } \\
\text { identified. }\end{array}$ & PP1 & $\begin{array}{l}\text { MODEL } 9 \\
\text { Planning/Executing } \\
\text { (6items) }\end{array}$ \\
\hline & & $\begin{array}{l}\text { A realistic time schedule was } \\
\text { developed for implementation of the } \\
\text { ASP when the program was initially } \\
\text { implemented. }\end{array}$ & PP2 & \\
\hline & & $\begin{array}{l}\text { The original plan for implementing the } \\
\text { ASP acknowledged clinicians' input } \\
\text { and opinions. }\end{array}$ & PP3 & \\
\hline & & $\begin{array}{l}\text { The original plan for implementing the } \\
\text { ASP was unnecessarily complex. }\end{array}$ & PP4 & \\
\hline & & $\begin{array}{l}\text { Nurses are actively engaged in the } \\
\text { ASP activities. }\end{array}$ & PP5 & \\
\hline & & $\begin{array}{l}\text { Clinical Pharmacists who provide } \\
\text { patient care on the inpatient wards are } \\
\text { actively engaged in ASP activities. }\end{array}$ & PP6 & \\
\hline & \multirow[t]{5}{*}{ Engaging } & \multirow{2}{*}{$\begin{array}{l}\text { The ASP has considerable visibility } \\
\text { within the hospital system. }\end{array}$} & \multirow[t]{2}{*}{ PE1 } & MODEL 10 \\
\hline & & & & Engaging (4 items) \\
\hline & & $\begin{array}{l}\text { The ASP had the support of the key } \\
\text { opinion leaders in the hospital. }\end{array}$ & PE2 & \\
\hline & & $\begin{array}{l}\text { I work well with the interdisciplinary } \\
\text { medical teams. }\end{array}$ & PE3 & \\
\hline & & I work well with individual clinicians. & PE4 & \\
\hline & \multirow{3}{*}{$\begin{array}{l}\text { Reflecting and } \\
\text { Evaluating }\end{array}$} & \multirow{2}{*}{$\begin{array}{l}\text { Clinical leadership at the hospital } \\
\text { provides staff with information on } \\
\text { hospital performance measures and } \\
\text { guidelines. }\end{array}$} & \multirow[t]{2}{*}{ PEV1 } & MODEL 11 \\
\hline & & & & Evaluation (5 items) \\
\hline & & $\begin{array}{l}\text { Clinical leadership at the hospital } \\
\text { establishes clear goals for patient care } \\
\text { processes and outcomes. }\end{array}$ & PEV2 & \\
\hline
\end{tabular}

*Constructs included in combined models are indicated by model number and number of total items displayed in column 4.

** Variable labels (e.g., EV1) match Fig. 1 indicating for which variable loading is reported. number. 


\begin{tabular}{|c|c|c|c|c|}
\hline \multirow[t]{5}{*}{ CFIR Domain } & CFIR Construct & Survey Item & $\begin{array}{l}\text { Variable } \\
\text { Label }\end{array}$ & CFA Models \\
\hline & & $\begin{array}{l}\text { Clinical leadership at the hospital } \\
\text { provides staff with feedback/data on } \\
\text { effects of clinical decisions. }\end{array}$ & PEV3 & \\
\hline & & $\begin{array}{l}\text { Clinical leadership at the hospital hold } \\
\text { staff accountable for achieving } \\
\text { results. }\end{array}$ & PEV4 & \\
\hline & & $\begin{array}{l}\text { Feedback from clinicians related to } \\
\text { proposed and implemented changes } \\
\text { of the ASP is collected regularly. }\end{array}$ & PEV5 & \\
\hline & & $\begin{array}{l}\text { Clinical leadership receives regular } \\
\text { feedback on progress of ASP activities } \\
\text { and resource needs. }\end{array}$ & PEV6 & \\
\hline \multicolumn{5}{|c|}{$\begin{array}{l}\text { *Constructs included in combined models are indicated by model number and number of total items displayed in column } \\
4 .\end{array}$} \\
\hline
\end{tabular}

\section{Study Recruitment and Participants}

We identified 329 antibiotic stewards at 154 hospital sites within our larger study. In January 2018, we sent emails from the investigative team to all stewards at each site inviting them to complete the survey online. A total of 182 stewards (55.3\%) responded to our invitation. At least one response was obtained from 126 hospitals (81.8\%). Stewards completed the surveys using the online platform REDCAP(28). Respondents reported their professional role and years acting in their role in addition to the CFIR structured questions (see Table 2 in Results). 


\begin{tabular}{|c|c|c|c|}
\hline Variable & $\begin{array}{l}\text { Total Sample } \mathrm{N}=182 \\
\text { (column \%) }\end{array}$ & $\begin{array}{l}\text { Physicians N = } 65 \\
\text { (column \%) }\end{array}$ & $\begin{array}{l}\text { Pharmacists } \mathrm{N}=118 \\
\text { (column \%) }\end{array}$ \\
\hline \multicolumn{4}{|l|}{ Health system } \\
\hline Intermountain Hospital & $27(14.8 \%)$ & $11(17.2 \%)$ & $16(13.6 \%)$ \\
\hline VA Hospital & $155(85.2 \%)$ & $53(82.8 \%)$ & $102(86.4 \%)$ \\
\hline \multicolumn{4}{|l|}{ Sex } \\
\hline Female & $92(50.5 \%)$ & $25(39.1 \%)$ & $67(56.8 \%)$ \\
\hline Male & $90(49.5 \%)$ & $39(60.9 \%)$ & $51(43.2 \%)$ \\
\hline \multicolumn{4}{|l|}{ Specialized Training } \\
\hline Yes & $132(72.5 \%)$ & $55(85.9 \%)$ & 77 (65.3\%) \\
\hline No & $47(25.8 \%)$ & $7(10.9 \%)$ & $40(33.9 \%)$ \\
\hline \multicolumn{4}{|l|}{ Steward Selection } \\
\hline Volunteered & $92(50.5 \%)$ & $33(51.6 \%)$ & $59(50.0 \%)$ \\
\hline $\begin{array}{l}\text { Expressed interest but assigned } \\
\text { role }\end{array}$ & $35(19.2 \%)$ & $11(17.2 \%)$ & $24(20.3 \%)$ \\
\hline Assigned role & $51(28.0 \%)$ & $17(26.6 \%)$ & $34(28.8 \%)$ \\
\hline \multicolumn{4}{|l|}{$\begin{array}{l}\text { Involvement in Stewardship } \\
\text { Program }\end{array}$} \\
\hline Primary leader & $40(22.0 \%)$ & $17(26.6 \%)$ & $23(19.5 \%)$ \\
\hline Co-lead & $107(58.8 \%)$ & $35(54.7 \%)$ & $72(61.0 \%)$ \\
\hline $\begin{array}{l}\text { Do a lot of the work but I'm not in } \\
\text { charge }\end{array}$ & $27(14.8 \%)$ & $6(9.4 \%)$ & $21(17.8 \%)$ \\
\hline Other & $27(14.8 \%)$ & $11(17.2 \%)$ & $16(13.6 \%)$ \\
\hline $\begin{array}{l}\text { Length of time facility (years)/ } \\
\text { median } \pm \text { IQR }\end{array}$ & $7.5 \pm 101$ & $7 \pm 12$ & $8 \pm 9$ \\
\hline $\begin{array}{l}\text { Length of time licensed (years) } \\
\text { median } \pm \text { IQR }\end{array}$ & $12 \pm 15$ & $15 \pm 12$ & $11 \pm 15$ \\
\hline Interest Value median \pm IQR & $97 \pm 23$ & $86 \pm 30.5$ & $99 \pm 18$ \\
\hline \multicolumn{4}{|l|}{ Specialized training- 3 missing } \\
\hline \multicolumn{4}{|l|}{ Steward selection- 4 missing } \\
\hline Involvement - 2 missing & & & \\
\hline
\end{tabular}

Data Management

The dataset was exported from REDCAP to R for analysis. The data was not normally distributed and thus, we treated the data as ordinal in our analyses, retaining the structure of Likert scale responses. We included responses from "strongly agree" to "strongly disagree" and excluded "don't know" from analyses. For hospitals with more than one survey respondent responses were aggregated at the hospital level by selecting at random from any ties between two participants and the most frequent response (2 out of 3), if there were 3 participants. Items related to the Outer Setting domain were excluded from further analyses due to the inadequate number of items $(n=2)$ for assessment using our modeling strategy. Additional items 
from CFIR constructs were also excluded from analyses because they did not have adequate item numbers $(n=1$ variable IIX; $\mathrm{n}=2$ variables LEX1 and LEX2) and attempts at combining with similar constructs did not meet fit indices thresholds. For transparency and to support other research these excluded items are included in Table 1.

\section{Descriptive Analyses}

We conducted descriptive analyses of demographic variables to understand the characteristics of individual stewards who participated - years of experience and leadership role.

\section{Confirmatory Factor Analyses}

To examine construct validity of our survey we conducted a CFA. CFA tests whether a measure of a construct is consistent with the expected construct, based on researcher expectations or theoretical foundations. We performed CFAs to assess whether the expected theoretically based CFIR construct from our survey on antibiotic stewardship implementation was supported by the survey data. To perform the CFAs we used the LAVAAN statistical package available in R(29-31).

Overall Modeling Strategy. Our modeling strategy was to fit single-factor models using the rating scales as reflective indicators. The ratings were treated as ordinal and estimation was by diagonally weighted least squares. The versions of single factor models estimated include those in which factor loadings could vary (congeneric models), and models in which factor loadings were constrained to be equal (tau equivalent). In general, we began with congeneric models. The variance of each model's latent factor was constrained to be one. We allowed correlations between indicator errors (uniqueness) where including the correlations was justified both statistically and in terms of the interpretation of the items (32).

\section{Model Structure}

For constructs with three or fewer indicators, we combined related constructs (see Table 1, column 4 for combined constructs) to test a total of 11 models. The choices related to combinations were made based on construct (e.g., constructs were only combined within the same CFIR domain), item number, and face validity of combinations. For example, in the Process domain, we combined the questions measuring Planning and Executing because these constructs are closely related (e.g., planning and executing the implementation), and because there were insufficient variables (2, below the threshold of 3 ) to examine the construct Executing in a single model. Reliability was examined on the combined structure of the models.

\section{Model Modifications}

Performing CFA demonstrates whether the data we have are a good fit to the structure of the theoretical framework we expect. There are standard modifications that can be examined when initial models do not have good fit(33). We used two of the most common of these modifications in some of our models that initially demonstrated non-optimal fit. Some models could not be statistically falsified (proven untrue, a necessary step for the model to be useful) as they lacked sufficient degrees of freedom. They were saturated models. In these cases, we explored whether imposing additional constraints (e.g., constraining loadings to be equal - a Tau-equivalent model) or un-constraining correlations between uniqueness modification indices) improved model fit. It is important to interpret models using modification indices with due discretion, as the indices are data driven, rather than theoretically driven(34). To improve model interpretation, we used modification indices only when there was sufficient theoretical justification for doing so, and we report each instance(32).

\section{Fit of the Models}

To assess model fit, we used widely recommended indices $(35,36)$. In these models we assessed Chi square (non-significant value $=$ good fit $)$, comparative fit index $(\mathrm{CFI}>.95=$ good fit $)$, the Tucker-Lewis index $(T L I>.95=$ good fit $)$, the root mean square error of approximation (RMSEA, $<.08=$ good fit) and standardized root mean square residual $(\mathrm{SRMR}<.08=$ good fit).

\section{Assessment of Reliability}


Cronbach's alpha and omega were used to assess internal consistency. Omega uses a more conservative standard with purportedly less bias, thus we present both(37).

\section{Results}

\section{Descriptive statistics}

The 182 survey respondents included 65 physicians and 118 pharmacists. Overall, $60 \%$ of individuals reported more than 5 years of work experience at the facility where they were employed and $72.5 \%$ of individuals reported having had specialized training (Table 2).

Examination of responses across sites for each model demonstrated a high level of endorsement of determinants for Evidence Strength and Quality/Relative Advantage, Self-Efficacy, and Engaging. For these constructs, means were $\geq 4.0$ indicating responses between Agree and Strongly Agree, with consistency exhibited across VA and IH sites (Fig. 1). Thus most sites found that the evidence behind ASPs was compelling and that their personal involvement was effective in engendering positive results for the program. In contrast, the construct Knowledge and Beliefs about the Intervention had a mean response of 2.9, which is between neutral and disagree. Items related to this construct are staff receptivity and burden on staff (reversescored, such that higher scores indicate lower burden). Thus, for some sites, there were beliefs that ASPs can be burdensome, unpopular, and overly restrictive.

Model modifications and missing data: Model assumptions were revised to allow correlations between errors in models for three constructs: "Leadership Engagement", "Knowledge and Beliefs about the Intervention", and "Engaging”. For Leadership Engagement, we allowed correlations between the error terms of the variables 1) mandate and champion and 2) mandate and intervention source. For knowledge and beliefs, we allowed correlations between the errors for the question about staff receptivity with the items related to staff understanding of the importance of the ASP. The justification for this modification is that the correlation of errors between these variables may represent a more complex unmeasured component of the construct. In the engaging model, correlations were allowed between variables representing 1) support "The ASP had the support of the key opinion leaders in the hospital" and 2) collaborative "I work well with the interdisciplinary medical teams).

One or more ordinal values were missing from one scale; for example, none of the site level responses resulted in a rating of "2" on the response scale for the items in the model Evidence Strength and Quality and Relative Advantage creating an error message in Lavaan. To address this, we reordered the ordinal factors with the integers that were present $($ e.g., 1, 3, 4, 5). In addition some cases were missing values for specific survey items. To address this, we omitted cases with one or more missing values from the estimation of any factor model. In some cases this slightly reduced the number of cases observed (e.g., to 118 from 121 for the model self-efficacy).

\section{Construct Validity - Confirmatory Factor Analyses}

For 5 models the basic congeneric model had adequate to good fit. For 3 models the tau-equivalent model provided the best fit (Table 3). Each final model had fit indices consistent with relatively good to good fit (Table 3, columns 3-8). 
Table 3

Models and internal consistency $(a, \theta)$ and indications of fit

\begin{tabular}{|c|c|c|c|c|c|c|c|c|c|c|}
\hline CFIR Domain & CFIR Construct & $\begin{array}{l}a \\
0\end{array}$ & $\begin{array}{l}\text { Chi- } \\
\text { square } \\
\text { (p) }\end{array}$ & df & RMSEA & $\mathrm{CFI}$ & TLI & SRMR & Cases & Modifications \\
\hline $\begin{array}{l}\text { Intervention } \\
\text { Characteristics }\end{array}$ & $\begin{array}{l}\text { Evidence Strength } \\
\text { \& Quality } \\
\text { Relative } \\
\text { Advantage }\end{array}$ & $\begin{array}{l}.96 \\
.92\end{array}$ & $\begin{array}{l}2.58 \\
(.28)\end{array}$ & 2 & .048 & 1.00 & 1.00 & .03 & 124 & None \\
\hline Inner Setting & $\begin{array}{l}\text { Networks \& } \\
\text { Communications/ } \\
\text { Relative Priority }\end{array}$ & $\begin{array}{l}.72 \\
.67\end{array}$ & $\begin{array}{l}.50 \\
(.78)\end{array}$ & 2 & .00 & 1.00 & 1.02 & .02 & 116 & $\begin{array}{l}\text { Tau- } \\
\text { equivalent } \\
\text { model }\end{array}$ \\
\hline & Culture & $\begin{array}{l}.89 \\
.83\end{array}$ & $\begin{array}{l}1.87 \\
(.39)\end{array}$ & 2 & $<.001$ & 1.00 & 1.00 & .03 & 119 & $\begin{array}{l}\text { Tau- } \\
\text { equivalent } \\
\text { model }\end{array}$ \\
\hline & $\begin{array}{l}\text { Implementation } \\
\text { Climate/ } \\
\text { Compatibility }\end{array}$ & $\begin{array}{l}.71 \\
.67\end{array}$ & $\begin{array}{l}1.97 \\
(.37)\end{array}$ & 2 & .00 & 1.00 & 1.00 & .04 & 109 & $\begin{array}{l}\text { Tau- } \\
\text { equivalent } \\
\text { model }\end{array}$ \\
\hline & $\begin{array}{l}\text { Readiness for } \\
\text { Implementation \& } \\
\text { Leadership } \\
\text { Engagement }\end{array}$ & $\begin{array}{l}.57 \\
.51\end{array}$ & $\begin{array}{l}8.16 \\
(.32)\end{array}$ & 7 & .04 & .997 & .994 & .06 & 109 & $\begin{array}{l}\text { Correlations } \\
\text { between } \\
\text { variable } \\
\text { errors }\end{array}$ \\
\hline & $\begin{array}{l}\text { Access to } \\
\text { Knowledge \& } \\
\text { Information }\end{array}$ & $\begin{array}{l}.63 \\
.58\end{array}$ & $\begin{array}{l}3.47 \\
(.18)\end{array}$ & 2 & .08 & .98 & .97 & .06 & 117 & $\begin{array}{l}\text { Tau } \\
\text { equivalent } \\
\text { model }\end{array}$ \\
\hline $\begin{array}{l}\text { Characteristics } \\
\text { of Individuals }\end{array}$ & $\begin{array}{l}\text { Knowledge \& } \\
\text { Beliefs about } \\
\text { Intervention/ } \\
\text { Individual } \\
\text { Identification with } \\
\text { Organization }\end{array}$ & $\begin{array}{l}.54 \\
.32\end{array}$ & $\begin{array}{l}42.77 \\
(.10)\end{array}$ & 32 & .06 & .99 & .99 & .08 & 109 & $\begin{array}{l}\text { Correlations } \\
\text { between } \\
\text { variables }\end{array}$ \\
\hline & Self-efficacy & $\begin{array}{l}.93 \\
.89\end{array}$ & $\begin{array}{l}19.36 \\
(.43)\end{array}$ & 19 & .01 & 1.0 & 1.0 & .05 & 118 & None \\
\hline Process & $\begin{array}{l}\text { Planning/ } \\
\text { Executing }\end{array}$ & $\begin{array}{l}.62 \\
.71\end{array}$ & $\begin{array}{l}7.79 \\
(.56)\end{array}$ & 9 & .00 & 1.00 & 1.00 & .05 & 109 & None \\
\hline & Engaging & $\begin{array}{l}.72 \\
.63\end{array}$ & $\begin{array}{l}.095 \\
(.76)\end{array}$ & 1 & .00 & 1.00 & 1.00 & .01 & 118 & $\begin{array}{l}\text { Correlations } \\
\text { between } \\
\text { variable } \\
\text { errors }\end{array}$ \\
\hline & $\begin{array}{l}\text { Reflecting and } \\
\text { Evaluating }\end{array}$ & $\begin{array}{l}.83 \\
.78\end{array}$ & $\begin{array}{l}11.94 \\
(.22)\end{array}$ & 9 & .06 & .99 & .99 & .07 & 101 & None \\
\hline
\end{tabular}

The standardized factor loadings, the common variance accounted for by the item within the model, varied from item-to-item for several models, particularly Knowledge and Beliefs about the intervention (.00-95) and Leadership Engagement (.17-98). (Fig. 2) A factor loading of 0 for item KB 10, "It is important to me that my hospital does not have substantially higher antibiotic use than other hospitals" suggests that it belongs in a different model. This item may be more closely related to competition as a driver for motivation rather than beliefs about the intervention. Item LE 1 "Our hospital primarily started the ASP because it was mandated" also had a particularly low loading. Potentially, this question did not work as well in the model because of the degree of perspective taking required to reflect on past motivations for persons other than the reporter. 
Ultimately, models with good fit indices can contain items with low factor loadings but if excluding the items is not theoretically sound items can be retained. These findings, coupled with scale indicators such as internal consistency, may guide future scale modifications.

Two measures of internal consistency were compared (37). The alphas ranged from moderate (.54 for Knowledge and Beliefs about the Intervention) to excellent (.96 for Evidence Strength and Quality/Relative Advantage). The more conservative indicator omega follows a similar pattern, with the same lowest scoring model and the same highest scoring model. Eight of the eleven models tested demonstrated adequate internal consistency (alpha >.70).

\section{Internal Consistency Reliability}

To assess discriminant validity, we examined correlations among models. Correlations below .80 are below threshold and indicate good discriminant validity. Correlations above .80 suggest measurement overlap between constructs. There was a single correlation above threshold, between the Reflecting \& Evaluating construct in the Process domain and Learning and Implementation Climate in the Inner Setting domain $r=.83$. All other models were correlated at levels below threshold, indicating acceptable discriminant validity.

\section{Discussion}

The goal of this study was to develop and psychometrically evaluate a CFIR-based measurement instrument in the context of ASP implementation. We assessed the responses to the survey to determine whether the survey questions within the models met our expectations of structure and consistency and whether the individual models are independent of each other (i.e., not highly correlated) and thus able to provide novel information. Although, we did not assess implementation in this paper, by validating this tool we are enabled to assess the relationship between implementation of stewardship programs and stewardship outcomes in future work. Our survey demonstrated face validity, construct validity as measured by CFA, internal consistency, and complete or marginal discriminant validity for all constructs. This indicates that our survey has psychometric validity. In future studies this survey measure can be used by researchers and quality improvement personnel to assess and report ASP implementation within and/or across ASPs. We also preliminarily demonstrated the level at which determinants of ASP outcomes were present across sites. Our evidence of the construct validity of a measure designed with the CFIR provides support for the CFIR structure and additional evidence for the robustness of the CFIR's theoretical underpinnings in the context of ASP.

In 2016, Clinton-McHarg and colleagues conducted a review of measures aligned with CFIR constructs and administered in public health and community settings (38). After examining 51 measures they found 5 of the 39 CFIR constructs were not measured by any of the measures evaluated: Intervention Source, Tension for Change, Engaging, Opinion Leaders, and Champions. The domains most often assessed were Inner Setting and Characteristics of Individuals. Few measures examined the Outer Setting and Process domains. Thus, this depth may be sacrificing the breadth of the CFIR. Validated measures that include multiple CFIR constructs, such as the survey described in this study, will advance the field of implementation science. Our survey also includes the frequently measured Inner Setting and Characteristics of Individuals domains, as well as the rarely measured Outer Setting and Process domains, including the Champions construct applied to the stewardship domain

(38). While other studies have demonstrated the validity of survey instruments intended to measure the Inner Setting domain and its component constructs $(39,40)$, our study is the first to confirm construct validity in a measure in the context of antibiotic stewardship using 4 out of 5 CFIR domains. We included all CFIR domains and 22 constructs for measurement. It is important to note that we did not validate the Outer Setting domain due to insufficient number of items, but we did validate 3 models within the Process domain and the construct Engaging: Champions. This speaks to the breadth of the flexible framework in the CFIR. In further work, other teams may consider adapting this survey to new domains. 
It is important to acknowledge that our models demonstrate the complexity of the CFIR. In some cases, our data was allowed to have correlated error terms between variables. These errors suggest that unmeasured variables remain. In the Leadership Engagement model, there is the potential for an unmeasured variable about the critical support from upper leadership and boots-on-the-ground providers, thus we allowed correlations between the errors for questions about the origin of the ASP "Our hospital primarily started the ASP because it was mandated" and about clinical champions, "There was an ASP-champion on the clinical staff who actively promoted the implementation of the ASP." We potentially identified an unmeasured variable representing the perception of a "compulsory" component of the ASP intervention demonstrated by both an external mandate and intervention push from leadership - the concept that "someone else pushes and promotes antibiotic stewardship." It is possible that stewards associate a leadership push with external pressure on leadership. Potentially, this information can support future research isolating facets of implementation that correlate with ASP success. For example, ASP implementations that are successful and established leadership engagement may be seen as more intrinsically motivated rather than inspired by a mandate - potentially an indicator of a mature program. Establishing this relationship could foster future methods for supporting stewards in developing mature ASPs in less time. Similarly, in the model for the CFIR construct "Knowledge and Beliefs about the Intervention," correlations were allowed between receptivity to the intervention and understanding of the intervention for nurses and pharmacists. There may be an unmeasured variable within the model that explains both receptivity and understanding importance - potentially related to a belief in the value of an ASP. One possibility is a variable representing support for a rational process of intervention (e.g., beliefs (importance) are expected to correlate with ASP related behaviors (receptivity). This finding could promote additional theoretical contributions to ASP development helping us to understand which environments may benefit from a Theory of Planned Behavior approach (essentially rational) and Social Cognitive approaches.

These theoretical frameworks undergird the CFIR which may suggest that using CFIR principles in ASP development as well as implementation will improve ASP performance. Our study shows a good fit for the data to the constructs measured, it also demonstrates that there may be a need to measure additional variables. This should be confirmed in subsequent work.

Discriminant validity was less robust ( .83 above the .80 threshold) between the Reflecting \& Evaluating model in the Process domain and Learning and Implementation Climate model in the Inner Setting domain. Processes of learning and implementation such as integration with the Electronic Health Record and encouragement of creativity relate to how sites reflect and evaluate performance by establishing clear goals and holding staff accountable. Relationships between these processes should be further evaluated. Our preliminary data suggests that across sites particular determinants may be important to pay attention to as possible harbingers of success. Self-efficacy was rated as highly present across sites as were Evidence Strength and Quality and Relative Advantage and Engaging. Future work will identify whether these determinants relate to site performance in ASP. In contrast, Knowledge and Beliefs about the Intervention were rated less highly suggesting potentially there was more variability across sites. In addition, Knowledge and Beliefs about the Intervention had poor internal consistency $(\alpha=.54)$, factor loadings that were particularly weak (e.g., "It is important to me that my hospital does not have substantially higher antibiotic use than other hospitals") suggesting this particular scale may need additional development to enhance the psychometrics for higher quality measurement of the constructs.

\section{Limitations}

Our results should be understood in light of the following limitations. First, we have a relatively small sample by CFA standards. Conducting analyses at the hospital site level may have influenced some of the domains and constructs, particularly those within the Characteristics of Individuals domain. A site level rating of Self-Efficacy may represent a combined "self" across respondents when answers by multiple individuals at a single site were different. Despite this limitation the data were a good fit to the models. Other constructs that were included for measurement (e.g., Cosmopolitanism) did not have adequate items to comprise a model nor face valid ways to combine with other constructs. Thus, although our survey advances the field, it could be more complete. In addition, our sample of Intermountain hospitals was too small to assess whether the construct validity for our survey was equally strong across different health systems, but further validation work with larger non-VA systems will allow this type of comparison.

Page $15 / 21$ 


\section{Conclusions}

Validated surveys are needed to assess the implementation processes of antibiotic stewardship across sites. There are surveys that provide information about stewardship activities, but many have focused primarily on establishing stewardship activities taking place across sites for comparison across time(41). This is important work to reveal the development of the content of antibiotic stewardship programming at hospitals. Information about the complex context of implementation of ASPs will also permit the design of ASPs that are more successful. One way that other survey studies have looked to assess mechanisms is to examine attitudes toward stewardship(42). Attitudes can be used to predict success, but by expanding measures to include forces that can change attitudes (e.g., Champions) we can develop a deeper understanding of what works, where and why. The implications of this information may well extend beyond ASPs to other complex implementation contexts.

In contrast to earlier work, the robust suite of CFIR constructs in our survey can be used to complement other data collection methods addressing stewardship implementation and promote understanding of implementation mechanisms underlying successes and failures. Incorporating our survey into study design can address how characteristics of individual stewards, such as those measured by the Self-Efficacy construct may influence changes over time in stewardship programming. For example, identifying connections between self-efficacy of individual stewards or a stewardship team and the specific changes in program options over time (such as program growth). In effect, use of our survey can address the contextual components of implementation in greater detail and its relationship to ASP outcomes than has previously been possible.

\section{Abbreviations}

Antibiotic Stewardship Programs (ASPs)

Confirmatory Factor Analysis (CFA)

Comparative fit index (CFI)

Consolidated Framework for Implementation Research (CFIR)

Root mean square error of approximation (RMSEA)

Standardized root mean square residual (SRMR)

Tucker-Lewis index (TLI)

Veterans Affairs (VA)

\section{Declarations}

In contrast to earlier work, the robust suite of CFIR constructs in our survey can be used to complement other data collection methods addressing stewardship implementation and promote understanding of implementation mechanisms underlying successes and failures. Incorporating our survey into study design can address how characteristics of individual stewards, such as those measured by the Self-Efficacy construct may influence changes over time in stewardship programming. For example, identifying connections between self-efficacy of individual stewards or a stewardship team and the specific changes in program options over time (such as program growth). In effect, use of our survey can address the contextual components of implementation in greater detail and its relationship to ASP outcomes than has previously been possible.

Ethics Approval: The Institutional Review Boards at Boston University and University of Utah reviewed and approved all study activities (U of Utah IRB \# 00099983). A waiver of documentation of consent was approved.

Consent for Publication: Not applicable.

Page 16/21 
Availability of Data and Materials: The datasets generated and/or analyzed during the current study are not publicly available due to data use restrictions but are available from the corresponding author on reasonable request with Institutional Review Board approval and a Data Use Agreement.

Competing Interests: The authors have no competing interests to be declared.

Funding: This work was funded the Agency for Healthcare and Research Quality (Grant Number 5R01HS025175-03).

Authors' Contributions: JB contributed to conception, analysis, and interpretation of this work and drafting all versions of the manuscript. EC, TB, MD, CR LD and MS contributed substantially to the conception of this work and the acquisition and interpretation of data. YZ JS and PT contributed to analysis of data. KMK, MG, and ES contributed substantially to the acquisition of data. All authors have reviewed, contributed to, and approved the final manuscript. All authors agree to be personally accountable for the authors own contributions.

Acknowledgements: The authors wish to thank Lynd Bacon for his support and expertise, the antibiotic stewards who participated in this research, Jessica Cole and Catherine Loc-Carrillo for their able management of this project, and Carrie Milligan for her editorial review.

Authors' Information (Optional): Not applicable.

\section{References}

1. Marston HD, Dixon DM, Knisely JM, Palmore TN, Fauci AS. Antimicrobial Resistance. JAMA. 2016;316(11):1193-204. doi:10.1001/jama.2016.11764. PubMed PMID: 27654605. Epub 2016/09/23.

2. Bell BG, Schellevis F, Stobberingh E, Goossens H, Pringle M. A systematic review and meta-analysis of the effects of antibiotic consumption on antibiotic resistance. BMC Infect Dis. 2014;14:13. doi:10.1186/1471-2334-14-13. PubMed PMID: 24405683; PubMed Central PMCID: PMCPMC3897982. Epub 2014/01/11.

3. Centers for Disease Control (CDC). Antibiotic resistance threats in the United States https://.pdf2019 [November 14, 2020.

4. ].

5. Baur D, Gladstone BP, Burkert F, Carrara E, Foschi F, Döbele S, et al. Effect of antibiotic stewardship on the incidence of infection and colonisation with antibiotic-resistant bacteria and Clostridium difficile infection: a systematic review and meta-analysis. Lancet Infect Dis. 2017;17(9):990-1001. doi:10.1016/s1473-3099(17)30325-0. PubMed PMID: 28629876. Epub 2017/06/21.

6. White AC Jr, Atmar RL, Wilson J, Cate TR, Stager CE, Greenberg SB. Effects of requiring prior authorization for selected antimicrobials: expenditures, susceptibilities, and clinical outcomes. Clin Infect Dis. 1997;25(2):230-9. doi:10.1086/514545. PubMed PMID: 9332517. Epub 1997/08/01.

7. Gross R, Morgan AS, Kinky DE, Weiner M, Gibson GA, Fishman NO. Impact of a hospital-based antimicrobial management program on clinical and economic outcomes. Clin Infect Dis. 2001;33(3):289-95. Epub 2001/07/05. doi: 10.1086/321880. PubMed PMID: 11438891.

8. Medicare Cf M, Services H, Medicare. and Medicaid Programs; Regulatory Provisions to Promote Program Efficiency, Transparency, and Burden Reduction; Fire Safety Requirements for Certain Dialysis Facilities; Hospital and Critical Access Hospital (CAH) Changes to Promote Innovation, Flexibility, and Improvement in Patient Care. Fed Regist. 2019;84(189):51732-834.

9. APPROVED: New Antimicrobial Stewardship Standard. Jt Comm Perspect. 2016;36(7):1. 3-4, 8. Epub 2016/08/24. PubMed PMID: 27548932.

10. Dellit TH, Owens RC, McGowan JE Jr, Gerding DN, Weinstein RA, Burke JP, et al. Infectious Diseases Society of America and the Society for Healthcare Epidemiology of America guidelines for developing an institutional program to enhance 
antimicrobial stewardship. Clin Infect Dis. 2007;44(2):159-77. Epub 2006/12/19. doi: 10.1086/510393. PubMed PMID: 17173212.

11. Policy statement on antimicrobial stewardship by the Society for Healthcare Epidemiology of America (SHEA). the Infectious Diseases Society of America (IDSA), and the Pediatric Infectious Diseases Society (PIDS). Infect Control Hosp Epidemiol. 2012;33(4):322-7.

12. Campion M, Scully G. Antibiotic Use in the Intensive Care Unit: Optimization and De-Escalation. J Intensive Care Med. 2018;33(12):647-55. Epub 2018/03/15. doi: 10.1177/0885066618762747. PubMed PMID: 29534630.

13. Kimura T, Uda A, Sakaue T, Yamashita K, Nishioka T, Nishimura S, et al. Long-term efficacy of comprehensive multidisciplinary antibiotic stewardship programs centered on weekly prospective audit and feedback. Infection. 2018;46(2):215-24. doi:10.1007/s15010-017-1099-8. PubMed PMID: 29134582. Epub 2017/11/15.

14. Pollack LA, Srinivasan A. Core elements of hospital antibiotic stewardship programs from the Centers for Disease Control and Prevention. Clin Infect Dis. 2014;59(Suppl 3):97-100. doi:10.1093/cid/ciu542. PubMed PMID: 25261548; PubMed Central PMCID: PMCPMC6521960. Epub 2014/09/28.. ; Suppl 3 ) .

15. Tebano G, Dyar OJ, Beovic B, Claudot F, Béraud G, Thilly N, et al. Practices, organisation, and regulatory aspects in advising on antibiotic prescription: the international ESCMID AntibioLegalMap survey. Infection. 2019;47(5):749-60. doi:10.1007/s15010-019-01298-2. PubMed PMID: 30903590. Epub 2019/03/25.

16. Tebano G, Dyar OJ, Beovic B, Béraud G, Thilly N, Pulcini C. Defensive medicine among antibiotic stewards: the international ESCMID AntibioLegalMap survey. J Antimicrob Chemother. 2018;73(7):1989-96. doi:10.1093/jac/dky098. PubMed PMID: 29635515. Epub 2018/04/11.

17. Graber CJ, Jones MM, Glassman PA, Weir C, Butler J, Nechodom K, et al. Taking an Antibiotic Time-out: Utilization and Usability of a Self-Stewardship Time-out Program for Renewal of Vancomycin and Piperacillin-Tazobactam. Hosp Pharm. 2015;50(11):1011-24. doi:10.1310/hpj5011-1011. PubMed PMID: 27621509; PubMed Central PMCID: PMCPMC4750836. Epub 2016/09/14.

18. Okedo-Alex I, Madubueze UC, Umeokonkwo CD, Oka OU, Adeke AS, Okeke KC. Knowledge of antibiotic use and resistance among students of a medical school in Nigeria. Malawi Med J. 2019;31(2):133-7. doi:10.4314/mmj.v31i2.5. PubMed PMID: 31452846; PubMed Central PMCID: PMCPMC6698627. Epub 2019/08/28.

19. Monsees E, Popejoy L, Jackson MA, Lee B, Goldman J. Integrating staff nurses in antibiotic stewardship: Opportunities and barriers. Am J Infect Control. 2018;46(7):737-42. doi:10.1016/j.ajic.2018.03.028. PubMed PMID: 29729830. Epub 2018/05/08.

20. Steward CD, Wallace D, Hubert SK, Lawton R, Fridkin SK, Gaynes RP, et al. Ability of laboratories to detect emerging antimicrobial resistance in nosocomial pathogens: a survey of project ICARE laboratories. Diagn Microbiol Infect Dis. 2000;38(1):59-67. doi:10.1016/s0732-8893(00)00161-9. PubMed PMID: 11025185. Epub 2000/10/12.

21. Chiotos K, Rock C, Schweizer ML, Deloney VM, Morgan DJ, Milstone AM, et al. Current infection prevention and antibiotic stewardship program practices: A survey of the Society for Healthcare Epidemiology of America (SHEA) Research Network (SRN). Infect Control Hosp Epidemiol. 2019;40(9):1046-9. doi:10.1017/ice.2019.172. PubMed PMID: 31311610. Epub 2019/07/18.

22. Damschroder LJ, Aron DC, Keith RE, Kirsh SR, Alexander JA, Lowery JC. Fostering implementation of health services research findings into practice: a consolidated framework for advancing implementation science. Implementation science: IS. 2009. doi:10.1186/1748-5908-4-50. PubMed PMID: 19664226; PubMed Central PMCID: PMCPMC2736161. ;4:50. Epub 2009/08/12.

23. Damschroder LJ, Lowery JC. Evaluation of a large-scale weight management program using the consolidated framework for implementation research (CFIR). Implementation science: IS. 2013;8:51. doi:10.1186/1748-5908-8-51. PubMed PMID: 23663819; PubMed Central PMCID: PMCPMC3656778. Epub 2013/05/15.

24. Robey N, Margolies S, Sutherland L, Rupp C, Black C, Hill T, et al. Understanding staff- and system-level contextual factors relevant to trauma-informed care implementation. Psychol Trauma. 2020. doi:10.1037/tra0000948. PubMed PMID: 
32915041. Epub 2020/09/12.

25. White MC, Randall K, Capo-Chichi NFE, Sodogas F, Quenum S, Wright K, et al. Implementation and evaluation of nationwide scale-up of the Surgical Safety Checklist. Br J Surg. 2019;106(2):e91-102. doi:10.1002/bjs.11034. PubMed PMID: 30620076; PubMed Central PMCID: PMCPMC6519364. Epub 2019/01/09.

26. Kirk MA, Kelley C, Yankey N, Birken SA, Abadie B, Damschroder L. A systematic review of the use of the Consolidated Framework for Implementation Research. Implementation science: IS. 2016. doi:10.1186/s13012-016-0437-z. PubMed PMID: 27189233; PubMed Central PMCID: PMCPMC4869309. ;11:72. Epub 2016/05/18.

27. Barlam TF, Childs E, Zieminski SA, Meshesha TM, Jones KE, Butler JM, et al. Perspectives of Physician and Pharmacist Stewards on Successful Antibiotic Stewardship Program Implementation: A Qualitative Study. Open Forum Infect Dis. 2020;7(7):ofaa229. doi:10.1093/ofid/ofaa229. PubMed PMID: 32704510; PubMed Central PMCID: PMCPMC7367692. Epub 2020/07/25.

28. CFIR Research Team- Center for Clinical Management Research. [webpage]. Ann Arbor, MI2020 [cited 2020 07_12_2020]. Available from: cfirguide.org.

29. Harris PA, Taylor R, Thielke R, Payne J, Gonzalez N, Conde JG. Research electronic data capture (REDCap)-a metadatadriven methodology and workflow process for providing translational research informatics support. J Biomed Inform. 2009;42(2):377-81. doi: 10.1016/j.jbi.2008.08.010. PubMed PMID: 18929686; PubMed Central PMCID: PMCPMC2700030.

30. Rosseel Y. lavaan: An R Package for Structural Equation Modeling. J Stat Softw. 2012;48(2):1-36.

31. R Core Team. R: A language and environment for statistical computing. 2013.

32. R Studio Team. RStudio: Integrated Development for R. Boston: RStudio PBC; 2020.

33. Curran Bauer Analytics. What are modification indices and should I use them when fitting sems to my own data? [cited 2020 November 10]. Available from: https://curranbauer.org/what-are-modification-indices-and-should-i-use-them-whenfitting-sems-to-my-own-data/.

34. Millsap RE, Everson H. Confirmatory Measurement Model Comparisons Using Latent Means. Multivariate behavioral research. 1991;26(3):479 - 97. Epub 1991/07/01. doi: 10.1207/s15327906mbr2603_6. PubMed PMID: 26776714.

35. MacCallum RC, Roznowski M, Necowitz LB. Model modifications in covariance structure analysis: the problem of capitalization on chance. Psychol Bull. 1992;111(3):490-504. doi:10.1037/0033-2909.111.3.490. PubMed PMID: 16250105. Epub 1992/05/01.

36. RB K. Methodology in the social sciences.Principles and practice of structural equation modeling. 4th ed.: Guilford Press; 2016.

37. Hooper DCJ, Mullen M. Structural Equation Modeling: Guidelines for deterimining model fit. Journal of Business Research Methods. 2008;6(1):53-60.

38. Dunn TJ, Baguley T, Brunsden V. From alpha to omega: a practical solution to the pervasive problem of internal consistency estimation. Br J Psychol. 2014;105(3):399-412. doi:10.1111/bjop.12046. PubMed PMID: 24844115. Epub 2014/05/23.

39. Clinton-McHarg T, Yoong SL, Tzelepis F, Regan T, Fielding A, Skelton E, et al. Psychometric properties of implementation measures for public health and community settings and mapping of constructs against the Consolidated Framework for Implementation Research: a systematic review. Implementation science: IS. 2016;11(1):148. Epub 2016/11/09. doi:10.1186/s13012-016-0512-5. PubMed PMID: 27821146; PubMed Central PMCID: PMCPMC5100177.

40. Fernandez ME, Walker TJ, Weiner BJ, Calo WA, Liang S, Risendal B, et al. Developing measures to assess constructs from the Inner Setting domain of the Consolidated Framework for Implementation Research. Implementation science: IS. 2018;13(1):52. doi:10.1186/s13012-018-0736-7. PubMed PMID: 29587804; PubMed Central PMCID: PMCPMC5870186. Epub 2018/03/29.

41. Walker TJ, Rodriguez SA, Vernon SW, Savas LS, Frost EL, Fernandez ME. Validity and reliability of measures to assess constructs from the inner setting domain of the consolidated framework for implementation research in a pediatric clinic 
network implementing HPV programs. BMC Health Serv Res. 2019;19(1):205. doi:10.1186/s12913-019-4021-5. PubMed PMID: 30925870; PubMed Central PMCID: PMCPMC6441163. Epub 2019/03/31.

42. Burgess LH, Miller K, Cooper M, Moody J, Englebright J, Septimus E. Phased implementation of an antimicrobial stewardship program for a large community hospital system. Am J Infect Control. 2019;47(1):69-73. doi:10.1016/j.ajic.2018.06.009. PubMed PMID: 30082089. Epub 2018/08/08.

43. Zetts RM, Garcia AM, Doctor JN, Gerber JS, Linder JA, Hyun DY. Primary Care Physicians' Attitudes and Perceptions Towards Antibiotic Resistance and Antibiotic Stewardship: A National Survey. Open Forum Infect Dis. 2020;7(7):ofaa244. doi:10.1093/ofid/ofaa244. PubMed PMID: 32782909; PubMed Central PMCID: PMCPMC7406830. Epub 2020/08/13.

\section{Figures}

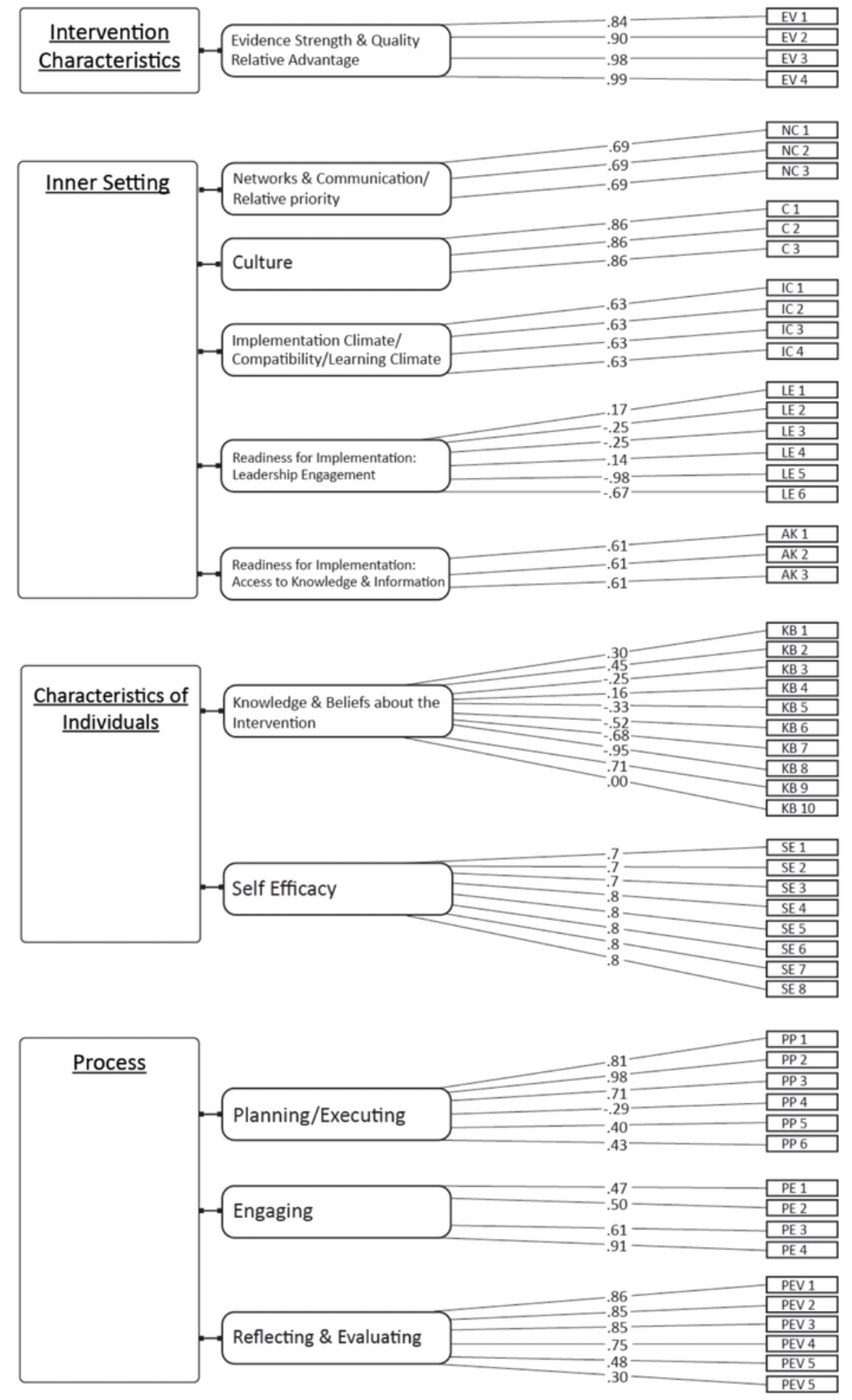

\section{Figure 1}


Standardized Factor Loadings for Model Variables. Note: Tau equivalent models were restricted to have identical factor loadings.

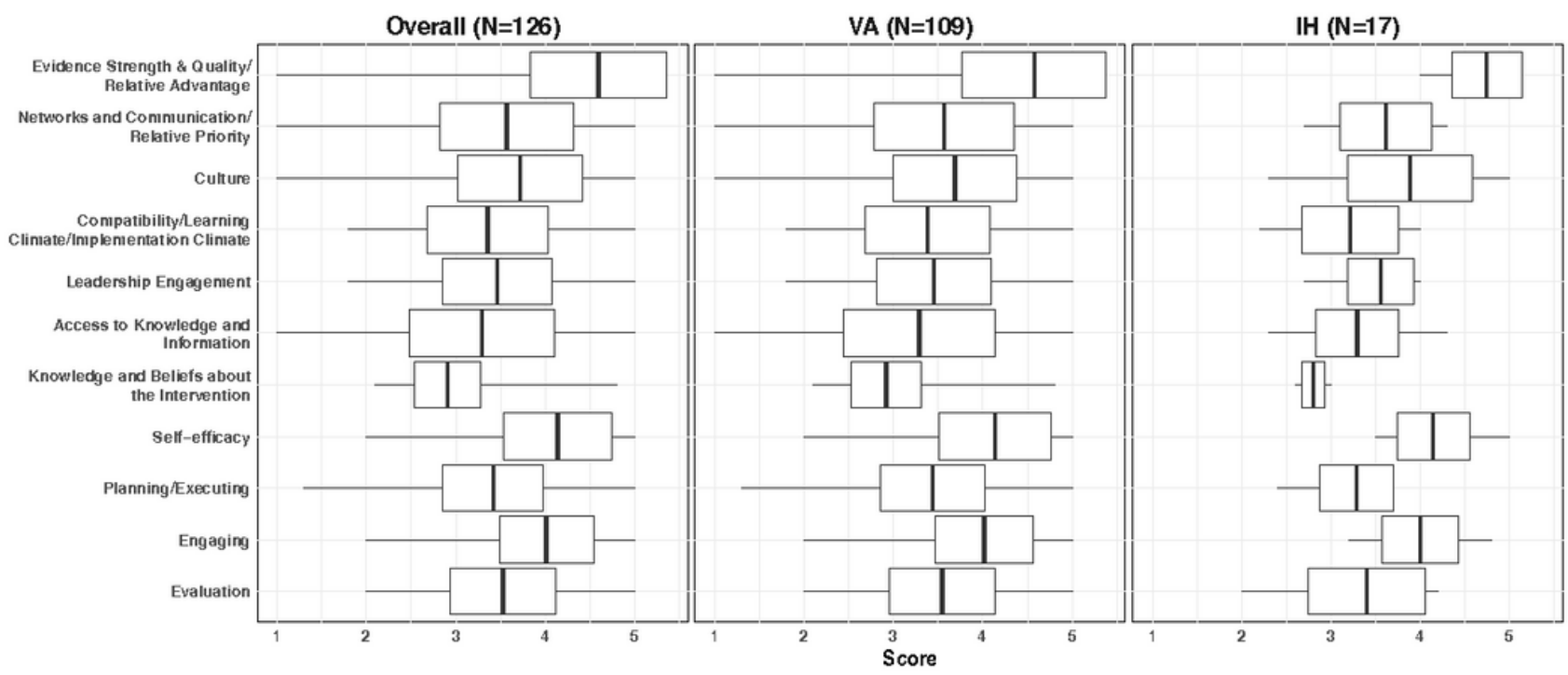

Figure 2

Mean and Range of Responses across sites and by site type (VA and IH)

\section{Supplementary Files}

This is a list of supplementary files associated with this preprint. Click to download.

- STROBEchecklistv4combinedButler.docx 